
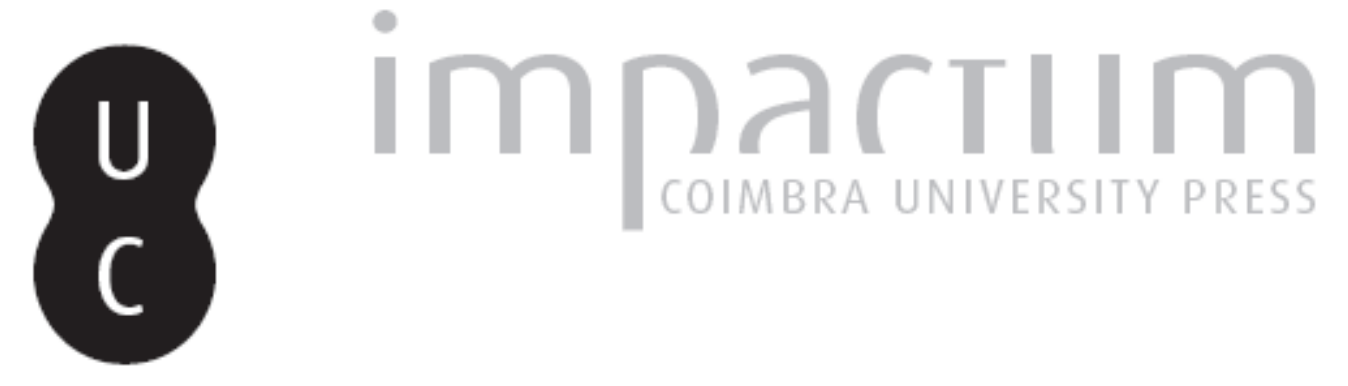

\title{
Mircea Eliade entre o «complexo» de Inés de Castro e de Maria Teles
}

Autor(es): Matos, Manuel Cadafaz de

Publicado por: Imprensa da Universidade de Coimbra

URL persistente:

URI:http://hdl.handle.net/10316.2/45334

DOI:

DOI:https://doi.org/10.14195/2183-8925_9-3_8

Accessed : $\quad$ 26-Apr-2023 13:46:37

A navegação consulta e descarregamento dos títulos inseridos nas Bibliotecas Digitais UC Digitalis, UC Pombalina e UC Impactum, pressupõem a aceitação plena e sem reservas dos Termos e Condições de Uso destas Bibliotecas Digitais, disponíveis em https://digitalis.uc.pt/pt-pt/termos.

Conforme exposto nos referidos Termos e Condições de Uso, o descarregamento de títulos de acesso restrito requer uma licença válida de autorização devendo o utilizador aceder ao(s) documento(s) a partir de um endereço de IP da instituição detentora da supramencionada licença.

Ao utilizador é apenas permitido o descarregamento para uso pessoal, pelo que o emprego do(s) título(s) descarregado(s) para outro fim, designadamente comercial, carece de autorização do respetivo autor ou editor da obra.

Na medida em que todas as obras da UC Digitalis se encontram protegidas pelo Código do Direito de Autor e Direitos Conexos e demais legislação aplicável, toda a cópia, parcial ou total, deste documento, nos casos em que é legalmente admitida, deverá conter ou fazer-se acompanhar por este aviso.

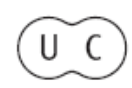




\section{REVISTA DE HISTÓRIA DAS IDEIAS 9}

\section{O SAGRADO E O PROFANO ***}

HOMENAGEM A J. S. DA SILVA DIAS

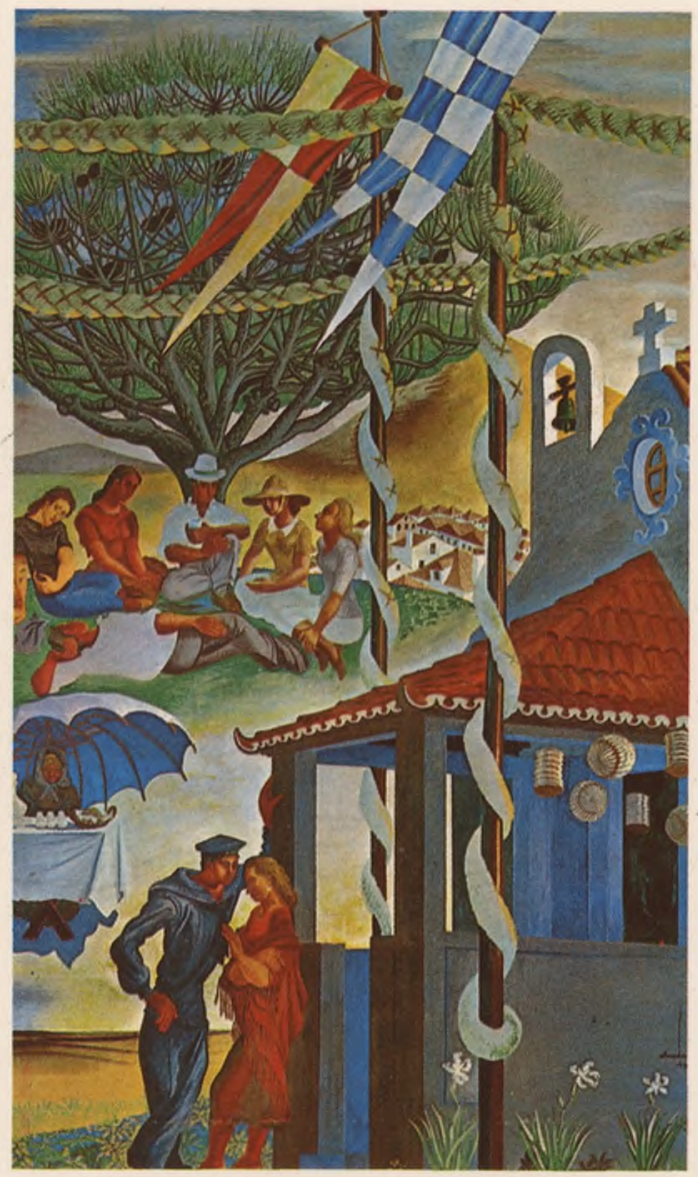

INSTITUTO DE HISTÓRIA E TEORIA DAS IDEIAS FACULDADE DE LETRAS 


\section{MIRCEA ELIADE ENTRE O «COMPLEXO» DE INÉS DE CASTRO E DE MARIA TELES}

Fomos surpreendidos, há não muitos meses atrás, com o desaparecimento (em 23 de Abril de 1986, em Chicago) de Mircea Eliade, romeno de nascimento, autor de uma multifacetada obra de investigação, particularmente no que respeita à Sociologia das Religiões, ao campo do Sagrado, da Mitologia, enfim, à Antropologia do Simbólico.

Este investigador, que contava 79 anos e deixou uma parte da vida ligada ao nosso país, é o obreiro de uma vasta e densa bibliografia que poderá ser subdividida em dois campos específicos. A primeira fase é aquela em que mais se votou à produção literária por assim dizer. Dela serão exemplo ilustrativo os romances Noite Bengali, de 1933 e Bosque Proibido, de 1955.

Numa segunda fase (que por vezes coincide, em alguns aspectos, com a primeira), agiganta-se a sua obra de antropólogo das religiões. São publicados, nesse âmbito, importantes trabalhos seus que passam logo a integrar planos (obrigatórios) de estudos em universidades de praticamente todo o mundo. É o caso de Tratado de História das Religiões (1949), Mito do Eterno Retorno (do mesmo ano), O Chamanismo e as Técnicas Arcaicas do Êxtase (1951), Imagens e Símbolos (1965), Mitos, Ritos e Símbolos (1975), bem como a História das Crenças e das Ideias Religiosas (dois volumes, editados em 1976 e 1978).

Interessou-nos primeiramente, em particular, duas obras suas, O Mito do Eterno Retorno (Lisboa, Edições 70, 1978)

\footnotetext{
* Antropólogo.
} 


\section{O Sagrado e o Profano}

e O Sagrado e o Profano (A Essência das Religiões) (Lisboa, Livros do Brasil, col. Vida e Cultura, sem data), em traduções para a nossa língua respectivamente a cargo de Manuela Torres e Rogério Fernandes. A primeira dessas obras tem a particularidade de ter sido (não sabemos se no seu todo mas) pelo menos finalizada quando ele vivia em Portugal.

É sabido que, entre 1942 e 1944, Mircea Eliade ocupou as funções de conselheiro cultural da Embaixada da Roménia em Lisboa. Após finalizar o desempenho de tais funções, este investigador - com quem tivemos ensejo de conversar um dia (anos setenta) em Paris - continuou a viver ainda durante algum tempo em Cascais, após o que abandonou Portugal, fixando-se em Paris e, mais tarde, nos Estados Unidos.

Autor de um ensaio (escrito em romeno) votado ao pensamento e acção de Salazar (1942), Eliade situou a acção do seu romance Bosque Proibido (1963) em Lisboa, Cascais e Coimbra.

\section{O espírito de Eliade devolvido a Portugal cerca de trinta anos depois}

A ligação de Eliade com Portugal não é, ao que se sabe, obra de ficção nem do acaso. Já é, porém, em uma sua obra de ficção que o autor de Romenos, Latinos do Oriente (1943), nos dá alguns retratos de Portugal, designadamente de Lisboa, Cascais e Coimbra. Tal sucede, com efeito, no seu romance intitulado Noaptea de Sanzienne 0) (A Noite de S. João), de 1955, que Maria Leonor Buescu verteu para a nossa língua em 1963, sob o título de Bosque Proibido.

$\mathrm{Na}$ sua «ausência americana» - longe dos romenos que o viram nascer em 1907 — este antropólogo das religiões escrevia, de Chicago, em Abril de 1960, para o nosso país, estas linhas que serviriam de prefácio à edição (de tal obra) em língua portuguesa:

«....Bosque Proibido é a mais importante das minhas obras literárias. Por isso, sinto-me feliz por ser a primeira que aparece em tradução portuguesa. Creio que, mais do que qualquer outro trabalho literário meu, este romance poderá interessar o leitor português. Passei cerca de cinco anos em Portugal, e uma parte da acção do romance

0) Mircea Eliade, Noaptea de Sanzienne, vertido para a língua portuguesa por Maria Leonor Buescu, Lisboa, Editora Ulisseia, 1963, prefácio. 


\section{Mircea Eliade}

decorre em Lisboa, Cascais e Coimbra; e, ao que me parece, é sempre interessante encontrar a paisagem natal e os compatriotas reflectidos pela sensibilidade de um escritor estrangeiro».

Apelando para o facto de que os portugueses se encontram dotados de uma concepção muito específica do Tempo, da Morte, da História e do Amor, Eliade — encontrando aí um bem vincado paralelismo com a vida do povo romeno - afirma que estas gentes conservam nessas facetas da vida social o carácter de mistérios.

A grelha de leitura aqui patenteada pelo autor de $\mathrm{O} \mathrm{Sa}$ grado e o Profano aproxima-o, em certa medida, da de um outro autor, o francês Raymond Abellio, no que concerne à análise da projecção do povo (navegador) português para a órbita do misterioso, do desconhecido e, consequentemente, da lenda e do mito-Oceano. A saga marítima portuguesa, que ganhou foros de alforia no século XIV, traduz, com efeito, um «investimento» no desconhecido, no risco, na aventura.

Sublinha, a este respeito, Abellio que

«toda a história de Portugal testemunha esta projecção num futuro tão indefinido como as grandes navegações onde este povo se procurou a si mesmo, aberto para o mar, não para a terra, e como partido para um grande retorno ao mais longínquo e, todavia, mais íntimo de si» $\left({ }^{2}\right)$.

O autor de Para um Novo Profetismo vai ao ponto de afirmar (3) que o homem do ocidente da Europa - o mesmo se verificando com a Califórnia em relação ao bloco dos Estados Unidos (a que, apenas aparentemente, se encontra ligado) — «se vê privado, diante do Oceano, de todo o horizonte material». Ele é, assim, como que rejeitado para o vazio até deparar com uma outra força, carga material, mítica e simbólica, o Extremo Oriente. Aquilo que para a Califórnia representará, já muito tardiamente, a procura de uma nova mítica - a mítica hollywoodesca do cinema — já no século XVI a índia (para nós) representava a projecção das novas frustrações, ambições e esperanças. A transgressão de uma outra Europa que se nos negava.

Questiona-se, a propósito, Abellio: «é o Quinto Império o cinema de Portugal?» Há que partir-se, com efeito, em di-

(2) Dominique de Roux, O Quinto Império, com prefácio^ de Raymond Abellio, Lisboa, Roger Delraux (editor), 1977. Prefácio cit., p. 13.

(3) Prefácio cit., p. 15. 


\section{O Sagrado e o Profano}

recção a novas coordenadas do saber e do sentir da problemática socio-cultural portuguesa nesse tempo de entrega à aventura, de rumo aos «mistérios» de que fala Mircea Eliade. Importa redescobrir, enfim, novas coordenadas do pensamento filosófico em relação a uma neo-interpretação da Historia da Cultura, designadamente no nosso país $\left({ }^{4}\right)$.

No romance Bosque Proibido Mircea Eliade ajuda-nos a reconstruir, em certa medida, a ideia que de Portugal tinha, em meados deste século, um visitante estrangeiro. Cascais já era, então, um ponto de conjugação (distanciada) entre a aristocracia (que iabjectava a grande e buliçosa Lisboa) e uma colmeia piscatória que se encontrava numa situação perfeitamente periférica, debatendo-se ainda com a mais variada gama de problemas.

Em 1915 haviam-se erguido, num frondoso parque não muito distante dali, as luxuosas termas do Estoril, consideradas, pela imprensa da época, um acontecimento notável na valorização turística da região. Os Cursos Musicais Internacionais de Férias e os concursos caninos também viriam, dentro de algum tempo, a adquirir uma significativa nomeada, levando para o estrangeiro o nome da famosa praia onde, «em 1871 EI Rei D. Luís mandou transformar a residência dos governadores da cidadela, já então apoucada no seu valor militar, numa casa capaz de recolher a família Real durante a época balnear» $\left({ }^{5}\right)$.

Eliade, com toda a sua carga humanizante, vai então espraiando o seu espírito por uma dualidade verdadeiramente notória. Por um lado as suas funções — de âmbito diplomático - em Lisboa, levam-no a conviver com os estratos sociais mais elevados, designadamente com a camada política. Isso leva-o, assim, a dedicar, em 1944, um ensaio a Salazar, trans-

$\left.{ }^{4}\right)$ Vide, a propósito, as considerações de um outro romeno, Vintila Horia, in Viagens aos Centros da Terra, Lisboa, Editorial Verbo, p. 143, que considera que a profunda originalidade da obra de Raymond Abellio (tanto a nível ensaístico como romanesco) se situa «na síntese dialéctica e criadora por ele operada entre o esoterismo, considerado como corpo de doutrina, ciência dogmática e estática, e a fenomenología transcendental de Husserl, considerada em última análise como comunidade agnóstica». Esta magnífica síntese encontra-se, aliás, formulada no prefácio de Rafael Gomes Filipe à obra de Abellio intitulada Para Um Novo Profetismo - Ensaio sobre o papel político do sagrado e a situação de Lúcifer no mundo moderno, Lisboa, Edições Arcádia, 1975. Prefácio, (p. 10).

$\left(^{5}\right)$ «Cascais e seus lugares», Revista de Cultura e Turismo, n. ${ }^{\circ}$ XVII, Fevereiro de 1963, p. 55. 


\section{Mircea Eliade}

parecendo, daí, em nosso entender, um apenas aparente «alinhamento» com o regime.

Longe de se deixar enredar pelas «teias do poder», Mircea Eliade é um homem que se sente vocacionado a reflectir — num âmbito filosófico (ou não) — sobre a «condição» do homem português. A sua sede de conhecer, tão profundamente quanto possível, o modo de ser e de viver das gentes portuguesas, leva-o a procurar não só conhecer um pouco da nossa língua $\left(^{6}\right)$ como, mais do que isso, a ler alguns dos nosso melhores autores. É por esta altura, com efeito, que a sua biblioteca se vai enriquecendo cada vez mais com alguns dos mais significativos nomes da História da nossa literatura $\left({ }^{7}\right)$, de Eça a Camilo, de Garrett a Junqueiro.

Essa sua disponibilidade e apetência para conhecer o país real que somos leva-o, também, a procurar no factor viagem um aliciante para ocupar os seus tempos livres. Mircea Eliade, nesses anos por que se deteve entre nós nas funções de conselheiro cultural da Embaixada da Roménia, realiza os mais variados périplos por terras portuguesas.

A sua maneira de observar as nossas gentes, de conviver com elas como estrangeiro que é, não deixará seguramente de se verificar em moldes de um natural distanciamento, de um certo «barroquismo». Um pouco antes desta estada de Eliade (de certo modo prolongada) entre nós, um outro estrangeiro, neste caso o catalão Eugênio d'Ors, havia de igual modo deambulado pelo nosso país, procurando alcançar um pouco do mais recôndito espírito das nossas gentes, do testemunho da sua cultura, designadamente das suas manifestações artísticas.

Foi precisamente d'Ors quem, sensibilizado pelo que auscultou do nosso povo, nos deixou este significativo testemunho:

«.... De Portugal provém metade do sentido secreto da história espiritual espanhola, de toda a história europeia provavelmente. Eu arriscaria que no composto designado

( $^{6}$ Vários autores, designadamente Victor Buescu, têm provado através dos seus estudos as aproximações de base entre o latim vulgar e a língua romena, como situados no âmbito das línguas da latinidade.

$\left.{ }^{7}\right)$ O autor agradece à prof. Maria Leonor Buescu esta informação. A sua família, ao que é sabido, travou estreita amizade com Mircea Eliade quando ele se encontrava a viver entre nós. Terá sido travada mesmo correspondência entre Victor Buescu e Eliade, o que ulteriores investigações nossas poderão comprovar. 


\section{O Sagrado e o Profano}

por Cultura, a Europa não apresentava, numa análise rigorosa, que dois corpos simples: Grécia e Portugal. O resto é, talvez, uma questão de dosagem» $\left.{ }^{8}\right)$.

E se Eugênio d'Ors, nessa visita ao Portugal real, se viu, por vezes, confrontado com algumas situações verdadeiramente inquietantes - como aquela em que, na Nazaré, teve de fazer parte de um júri em que se elegia a rainha das mulheres da praia - Mircea Eliade também se terá seguramente confrontado, nesses anos quarenta, com algumas situações de «deslumbramento».

\section{O autor de «O Sagrado e o Profano» entre o complexo de Inés e o de Maria Teles}

Uma das situações que temos conhecimento é aquela de que nos dá testemunho, precisamente no seu livro Bosque Proibido (de ficção, como referimos atrás), da vivência episódica de um dos seus personagens precisamente na cidade de Coimbra.

Acerca da sua chegada a esse burgo milenário refere, com efeito, o autor:

«Toda a gente julga que estou em Madrid, mas desci no Entroncamento e tomei o comboio para Coimbra. Sem saber o dia certo sabia que você havia de vir aqui... Sabia que havia de vir à fonte de Inès de Castro e foi lá que o esperei todos estes dias. Chegava de manhã e só me ia embora à noite. Disse às pessoas que queria escrever qualquer coisa sobre Inês. Um rapaz ofereceu-se para me explicar a lenda em pormenor: Inês sentava-se numa pedra e esperava uma carta que lhe mandava D. Pedro. D. Pedro enviava-lhe as cartas numa caixinha que deixava boiar arrastada pelas águas da fonte» $\left({ }^{9}\right)$.

Tal vivência, ao ser colocada por Mircea Eliade numa das personagens femininas desse romance mais não significa, afinal, do que o seu próprio encontro com esta lenda (baseada, embora, em factos reais). É por demais sabido, com efeito, que o assassínio de Inês de Castro, em 7 de Janeiro de 1355, foi um acontecimento propício ao aparecimento de uma infinitude de lendas, contos, relatos ou meras historietas de circunstância.

(8) Eugênio d'Ors, Du Baroque, Paris, Gallimard (1935), Col. Idées, 1983, p. 139.

(9) Mircea Eliade, ob. cit., p. 349. 
Vindo a ocupar um lugar de destacado relevo no folclore ou na tradição literária (oral) coimbrã, a morte de Inès de Castro ergueu-se alto e fez «desaparecer» outros destacados corpos de «romance» desta mesma época. O assassínio da «linda Inés» como tronco dominante de uma série de outros «romances» terminados em tragédia, fez com que se eclipsassem - por a própria tradição oral (e até mesmo a escrita) os haver claramente secundarizado - uma série de outros de significativa importância histórico-cultural para a época. O mais destacado deles será, porventura, o não menos dramático assassínio de D. Maria Teles, irmã de D. Leonor Teles - precisamente às mãos de seu marido, o príncipe D. João, por sinal filho da própria D. Inès de Castro e de D. Pedro - em data que Anselmo Braamcamp Freire supõe ter sido em Novembro de $1379\left({ }^{10}\right)$.

Este acontecimento, a que historiadores como António Borges Coelho não deixam de reconhecer uma significativa importância no seu grau e carga transgressora, movimentou um outro corpus de lenda. O facto é, quanto a nós, por demais evidente. A lenda (e facto consumado, nunca é demais frisar) do assassínio de Inês assumiu-se como tronco dominante na criatividade oral popular da época, e épocas imediatamente posteriores, designadamente durante a segunda metade do século XIV e praticamente durante o século XV. Isso levou a que ela mesma fizesse passar à condição de troncos subalternizados ou aparentemente a-significantes, acontecimentos matéria de lenda como o da morte de D. Maria Teles.

O assassínio de Inês reflectiu-se na obra de autores como D. Francisco Manuel de Mello, em particular nos seus Doze Sonetos por Varias Acciones publicados em 1628. Ele tingiu de tal forma de rubro a imaginação popular coimbrã (e até mesmo nacional) da segunda metade do século XIV que, dali em diante, tudo o que pudesse ser assumido como «terror» na imagística popular ou popularizante da época, não se lhe poderia — ou conseguiria — igualar. A tónica dominante impedia, assim, a subalterna de entrar na imagística popular: o predicado violava a capacidade de afirmação do complemento; o tempo de origem fazia calar o tempo de sequência, o grito abafava o próprio eco.

(10) Vide Damião Peres, Capítulo (XXIII) «O fim da Dinastia de Borgonha», in História de Portugal (Edição monumental comemorativa do $8 .^{\circ}$ Centenário da fundação da nacionalidade), vol. II, Barcelos, MCMXXIX, p. 357. 
Mircea Eliade não é estranho, na visita que faz em plenos anos quarenta à fonte dos Amores, em Coimbra, a esta própria dialéctica da máquina do tempo. Também para si a voz de Inés sonegou a de María Teles. O som palatal (convertido em escrita) eclipsou a «voz» interior do próprio mestre. $O$ punhal que matou Inès foi arma mais mortífera que aquele que, segundo Femão Lopes, fez calar a voz e a vida daquela jovem (Maria) esposa de D. João: «...e esta foi sua postumeira pallavra, damdo o sprito, e bofando mujto samgue delia. Oo piedade do muj alto Deos, se emtom fora tua merçee de botares aquel cruel cujtello, que nom dampnara o seu alvo corpo, inoçemte de tam torpe culpa» $\mathrm{O}^{1}$ ), brada a voz desalentada do autor da Crónica de D. Fernando.

Neste caso o assassínio de Inés materializa o início do fenómeno morte, remete-nos até ao assassínio de Abel por seu irmão Caim. A voz «estrangulada» de Inés matou o grito de Maria. Uma é o tempo basilar ou do início das coisas (ou dos factos), a raiz temporal de uma cosmogonia do absurdo; a outra é o tempo subsequente, interrompido na ficção e na criação (poética ou poiética) dos homens. Delas só a primeira é virtualizada como um tempo de sagrado.

Mircea Eliade, no seu conjunto de referências sobre a micro-componente da origem, acaba por encontrar, afinal, uma grelha de leitura para esta problemática:

«O tempo de origem por excelência, é o tempo da cosmogonia, o instante em que apareceu a mais vasta realidade, o Mundo. É por essa razão que a cosmogonia serve de modelo, exemplar a toda a criação, a toda a espécie de fazer. É pela mesma razão que o Tempo cosmogónico serve de modelo a todos os tempos sagrados» (12).

Deslumbrado pelo «todo» do caso de Inés, Mircea Eliade ignora assim, em Coimbra, o outro todo, o de Maria Teles. $\mathrm{Ou}$ talvez que, mesmo ignorando (historicamente) o segundo caso, ele sintetize todos os acontecimentos - e as respectivas implicações ao mais vasto nível - concentrados no primeiro, no papel da vítima expiatória imolada.

A posição assumida por D. Afonso IV (em relação aos seus conselheiros Coelho, Gonçalves e Lopes Pacheco) no sentido de que «fizessem o que quisessem» - em relação à vida

$\left.\mathrm{O}^{1}\right)$ Fernão Lopes, Crónica do Senhor Rei Dom Fernando, Porto, Livraria Civilização, 1979, pp. 283-284.

(12) Mircea Eliade, O Sagrado e o Profano - A essência das Religiões, Lisboa, Edições Livros do Brasil, Col. Vida e Cultura, (Capítulo «Regeneração pelo regresso ao tempo original»), sem data, p. 93. 


\section{Mircea Eliade}

de Inès de Castro - mais não é, afinal, do que a mesma atitude tomada catorze séculos antes quando da morte de Cristo ou João Baptista. A este respeito René Girard dá-nos uma leitura bastante coerente de todo o processo, quando sublinha que neste mundo as potências se encontram verdadeiramente divididas em em dois grupos não simétricos, as autoridades constituídas, por um lado, e as multidões, por outro $\left({ }^{13}\right)$.

Regra geral, preconiza Girard, as primeiras arrastam as segundas. Em período de crise, porém, sucede o inverso. Dá-se então como que uma amálgama de interesses que ganha forma na existência - e consequentemente processo de expiação - de um bouc émissaire. Ele mais não é, afinal, do que um intermediário do sagrado.

Nestes períodos, saliente-se ainda, a multidão é tão poderosa - e Silva Dias numa recensão crítica ${ }^{14}$ ) publicada em 1984 dá-nos igualmente disso testemunho - que

«não tem necessidade de parecer toda a comunidade para obter os resultados mais surpreendentes. As autoridades constituídas inclinam-se perante ela e cedem-lhe as vítimas que reclama o seu capricho, da mesma forma que Pilatos cede Jesus, Herodes ou João Baptista» $\left({ }^{15}\right)$.

Inès, vítima expiatória. Maria Teles, foi-o também. $\mathrm{O}$ apego de Mircea Eliade ao primeiro desses corpos de lenda, traduz, na sua grelha de leitura, o seu modus interpretandis (mesmo dissimulado, por se estar ante uma obra romanceada) da génese da violência. Não da violência perpetrada pelos conselheiros de Afonso IV à esposa amada de D. Pedro, mas de todas as mulheres oprimidas, transviadas do raid da felicidade linearmente térrea, liminarmente terrena. A morte de D. Inès (ou D. Maria Teles) evocada (ou não) pelo autor de O Mito do Eterno Retorno, mais não representa, afinal, de que uma descida até à génese da violência e do sangue derramado, de uma forma ritualizada, sacrificialmente. Tratar-se-á afinal, de um eterno retorno, talvez às origens ou ao desconhecido.

(13) René Girard, Le Bouc Émissaire, Paris, Éditions Grasset et Fasquelle (ed. em «livre de poche»), 1982, p. 171.

(14) J. S. da Silva Dias, notícia de recensão a Le Bouc Émissaire, Paris, Cult. Hist. Fil. 3, 1984, pp. 403-405.

$\left.{ }^{15}\right)$ René Girard, idem, ibidem. 


\section{O Sagrado e o Profano}

\section{O eterno retorno... mas para onde?}

Até onde o conhecimento antropológico — nesta grelha de leitura dos acontecimentos históricos ou em outros - nos permite alcançar uma legi(timi)(bili)dade dos factos. Teremos que regredir sempre até às mais remotas origens? $\mathrm{O}$ velho «retorno» será sempre o lúcido argumento de antropólogos, semioticistas e videntes? O que está enterrado, afinal, nas alfombras do passado (entre o machado de guerra da minoria étnica e o super-povoado-poluído?) Será o triunfo (esperado) da tónica cultural dominante sobre a tónica subalterna $\left({ }^{16}\right)$ ?

Numa das suas obras teóricas fundamentais, $O$ Mito do Eterno Retorno, Mircea Eliade sublinha, porém (na introdução) que, para além das linhas subalternas, foi sua preocupação «detectar as principais linhas de força no campo especulativo das sociedades arcaicas».

Defendia já aí o autor — nesses finais dos anos quarenta - que a filosofia ocidental se arrisca a «provincializar», quer encerrando-se na sua própria tradição e ignorando os problemas e as soluções do pensamento oriental, quer ao obstinar-se a reconhecer apenas as «situações» do homem das civilizações históricas, em detrimento da experiência do homem «primitivo» das sociedades tradicionais.

Posições não menos polémicas são defendidas por Mircea Eliade (cuja tese de licenciatura foi subordinada — após uma estada num mosteiro dos Himalaias, em Rishikesh — à problemática do yoga), na obra $O$ Sagrado e o Profano.

Neste seu trabalho o autor procura reflectir, designadamente, sobre o comportamento do homo religioso, como uma manifestação de comportamento geral ( $\left.{ }^{17}\right)$. Para este autor, com efeito,

«os modos de ser sagrado e profano dependem das diferentes posições que o homem conquistou no Cosmos e, por conseguinte, interessam não só ao filósofo mas também a todo o investigador desejoso de conhecer as dimensões possíveis da existência humana».

(16) A noção de cultura subalterna foi definida, de forma precisa, por Silva Dias - embora numa esfera de conhecimento que se prende não já com a Idade Média mas com a problemática do Humanismo e Renascimento (tão cara a amigos nossos como os profs. José V. de Pina Martins, Américo da Costa Ramalho ou Justino Mendes de Almeida), in "Camões e a Cultura Portuguesa subalterna no século X VI», Expresso, 10 de Abril de 1980.

(17) Este seu estudo insere-se, a nosso ver, em ópticas que não andam distanciadas nem da Fenomenologia, nem da Psicologia nem da Antropologia Filosófica. 


\section{Mircea Eliade}

Esta problemática prende-se, afinal, com o ser essencial dos portugueses que Eliade, na sua «peregrinatio ad loca infecta», conheceu muito de perto. Nesse seu deambular pelo mundo - entre a sonhadora Bucareste natal, a Lisboa tele-comandada governamentalmente por Salazar, ou a Chicago fim-de-estação (vivencial) — Mircea Eliade assumiu a sua feição de aventureiro, de instigador de conhecimentos inovadores, de diálogos com a outra dimensão, sendo porventura a maior delas a do sagrado. Eliade aventureiro, mas também exilado, de si próprio.

Não escrevera ele, no seu próprio diário:

«....Cada exilado é um Ulisses a caminho de ícaca. Toda a existência real reproduz a Odisseia, o caminho para ítaca, para o centro. $O$ exilado deve ser capaz de penetrar no sentido secreto das suas vagabundagens, e compreendê-las como outras tantas provas iniciáticas que o levam para o centro. Cada um vai para sua casa com as suas próprias pernas, com os seus próprios males».

Exilado também de si próprio - não estabelecera já o poeta turco Nazim Hikmet, quando no cativeiro no seu próprio país, a si mesmo essa mesma pena - o antropólogo das religiões procura apenas novas formulações de novas interrogações. Respostas, essas, encontrá-las-á?

Ele mais não encontra no seu percurso, afinal, tal como muito bem teorizou o seu compatriota romeno Dumitru Micu (18), do que «um estado de alegria eufórica» numa «grandeza heroica».

Um aventureiro como Eliade, frisa Micu,

«é um espírito que se eleva para além da sua condição humana comum. A bravura exprime-se não apenas nas circunstâncias espectaculares, mas também pela solidão, pela leitura e pela criação. Os escritos de Eliade - as suas obras de erudição e as literárias - traduzem de forma significativa as aventuras do espírito do autor».

Eliade deixou-nos há pouco, mas apenas por breves instantes. As suas teorias (por enquanto ainda perenes) são ainda prenhes de energia tanto nas universidades deste como de qualquer outro dos continentes ditos da Terra. Ele partiu, apenas por momentos. Como o deixámos, afinal, circunstancialmente de ver (até sempre), no momento em que sem qualquer aceno se despediu de nós quando nos anos setenta o encontrámos em Paris.

3, Março de 1982.

$\left.\mathrm{C}^{18}\right)$ Dumitru Micu, «Mircea Eliade à 75 ans», La Roumanie, 